\title{
EXERCISE INDUCED CHANGES OF GASTROESOPHAGEAL ACIDITY IN CHILDREN
}

\author{
C. Pacchiarotti, M. Barreto, C. Casini, F. La Penna, A. Crescenzi, M.C. Paolino, M.P. Villa \\ Pediatric Unit, NESMOS Department, Sant'Andrea Hospital, Faculty of Medicine and Psychology, \\ University "La Sapienza", Rome, Italy
}

Background: Gastroesophageal reflux (GER) is often related to recurrent respiratory symptoms. Whether GER accounty for exercise-induced bronchoconstriction remains underdebate.

Aims: To compare the gastroesophageal acidity $(\mathrm{GE} \mathrm{pH})$ with lung function during exercise in children with recurrent respiratory symptoms.

Methods: In 12 asthmatic and 9 non-asthmatic (aged 5.9 -15.8 yr, M/F 14/7) we assessed spirometry, then started a 24-h $\mathrm{GE} \mathrm{pH}$ monitoring $\left(\mathrm{GE}_{\mathrm{pH}} \mathrm{H}_{24}\right)$. In a second session, they did a 6-minutes treadmil-exercise testing followed one hour later by gastroesophageal catheter removal. Prick test and blood samples for IgE and leukocytes were also measured, the sum of allergen-skin wheals was termed "prick index".

Results: Median (IQR) GE $\mathrm{pH}_{24}$ values were found unrelated to post-exercise $\mathrm{FEV}_{1}$ decrease. GE $\mathrm{pH}_{24}$ correlated with prick index $(\mathrm{r}=0.58)$, percent blood eosinophils $(\mathrm{r}=0.58)$ only in asthmatic children $(\mathrm{p}<0.05)$; they also yielded higher GE $\mathrm{pH}_{24}$ than non-asthmatic children (7.25, IQR 0.18 vs 7.0, IQR 0.50; $<<0.05$ ). GE $\mathrm{pH}$ recorded 6 minutes before exercise decreased during exercise testing from 7.85 (IQR 0.73 ) to 7.30 (IQR 1.05) in asthmatic ( $\mathrm{p}=0.059)$ while increased from 7.20 (IQR 0.90) to 7.90 (IQR 0.85) in non-asthmatic children ( $\mathrm{p}=0.043$ ). One-hour post-exercise GE pH increased only in asthmatic children ( 7.80, IQR 0.68; $\mathrm{p}<$ $0.05)$.

Conclusion: Exercise-induced changes of GE pH in asmathic children are presumably related to vagalinduced mechanisms. These mechanisms seems to be enhanced by atopic inflammation. 